\title{
Auditory evoked neuromagnetic response in cerebrovascular diseases: a preliminary study
}

Kazunori Toyoda, Setsuro Ibayashi, Tomoya Yamamoto, Yasuo Kuwabara, Masatoshi Fujishima

\begin{abstract}
Objectives-Magnetoencephalography (MEG) measures aspects of the function of the auditory cortex of the human brain with high spatial resolution. The objective was to determine whether MEG also accurately identifies the auditory cortex of the brain in patients with ischaemic stroke.

Methods-The auditory evoked magnetic field (AEF) was examined after stimuli of $1 \mathrm{kHz}$ tone bursts in 24 stroke patients without apparent infarcts in the auditory cortex, and compared the topography of sources of $50 \mathrm{~ms}$ (P50m) and $100 \mathrm{~ms}$ latency deflections $(\mathrm{N} 100 \mathrm{~m})$, the most prominent components of middle and long latency AEFs, with that of 12 normal subjects. Cerebral haemodynamics in and around the auditory cortex were evaluated using PET.
\end{abstract}

Results-In nine of 24 stroke patients, the accurate magnetic sources of $\mathrm{P50m}$ or N100m were not identified. The distribution of $150 \mathrm{~m}$ sources varied more widely than $\mathbf{N 1 0 0 m}$. Eight of these nine patients had severe stenotic lesions in the carotid or middle cerebral arterial trunks. Patients with abnormal $P 50 \mathrm{~m}$ responses had decreased supratemporal and hemispheric blood flow compared with patients with normal P50m responses.

Conclusions-These findings suggest that large vessel disease with disturbed cerebral haemodynamics in and near the auditory cortex tend to affect AEFs, especially the middle latency components. This is the first combined study of MEG and PET to show a significant correlation between AEF responses in stroke patients and their PET indices.

(f Neurol Neurosurg Psychiatry 1998;64:777-784)

Keywords: magnetoencephalography; positron emission tomography; functional mapping; ischaemic stroke

Auditory stimuli elicit several magnetic responses-auditory evoked magnetic fields (AEFs) - in the human brain. ${ }^{1}$ In the same way as auditory evoked electric potentials (AEPs), AEFs consist of multiple components with early, middle, and long latency. The first represents brain stem responses, and the other two indicate responses in the higher auditory system. $^{2}{ }^{3}$ The most prominent deflections in the middle and long latency AEFs peak at about 40 to $50 \mathrm{~ms}$ (P50m) and $100 \mathrm{~ms}$ $(\mathrm{N} 100 \mathrm{~m})$ after sound onset, respectively. ${ }^{3-5}$
Magnetoencephalography (MEG) permits the mapping of the auditory cortex accurately and non-invasively based on AEFs, although this technique is primarily sensitive to tangential, and not to radial sources. The assumed spatial accuracy of MEG with respect to landmarks on the head was reported to be within 3 $\mathrm{mm} .{ }^{6}$ Both $\mathrm{P} 50 \mathrm{~m}$ and $\mathrm{N} 100 \mathrm{~m}$ are generated in the auditory cortex in the supratemporal plane by combining data derived via MEG and MRI. ${ }^{6-9}$ By contrast, the normal profiles of AEFs as disclosed by MEG have not been recorded in some patients with auditory cortical lesions; the auditory response patterns were reported to be totally absent, fairly small, or extremely large in patients with large temporal lobe infarcts. ${ }^{10} 11$ On the other hand, patients with infarcts near the supratemporal cortex were shown to have normal responses. ${ }^{11}$

In large vessel cerebrovascular disease, cerebral haemodynamics are often disturbed in broad territories and various hemispheric syndromes are found, even if the infarct documented on MRI is minimal. Occlusive lesions of the carotid and middle cerebral arterial trunks alter auditory cortical circulation and may affect AEFs. The first goal of this study was to examine the hypothesis that MEG may disclose abnormality of the auditory cortex which was not observable in MRI based on AEF responses in stroke patients with large vessel disease.

Positron emission tomography (PET) is a three dimensional imaging technique of brain function. Some PET indices, including regional cerebral blood flow (CBF) and cerebral metabolic rate of oxygen $\left(\mathrm{CMRO}_{2}\right)$, reflect focal brain activity. These indices have been reported to correlate with electrophysiological findings such as visual evoked potentials and quantitative EEG. ${ }^{12}{ }^{13}$ The second goal of this study was to determine whether abnormalities of PET indices in the auditory cortex correlate with abnormal AEF responses.

\section{Subjects and methods}

SUBJECTS

Twenty four right handed patients with chronic non-embolic minor brain infarction (19 men and five women, age range 34 to 75 years) participated in this study. Patients with hearing difficulty and patients without sufficient intellect or endurance for the MEG and PET studies were excluded. Infarcts and causal vascular diseases were evaluated using brain MRI and magnetic resonance angiography (MRA, Sigma System, 1.5 T, GE Co) for all patients. Cervical and transcranial neurosonography 
Table 1 Clinical characteristics of the patients

\begin{tabular}{|c|c|c|c|c|c|c|c|}
\hline Patient no & $\operatorname{Age}(y) / \operatorname{sex}$ & $\begin{array}{l}\text { Stroke } \\
\text { subtype }\end{array}$ & $\begin{array}{l}\text { Affected } \\
\text { side }\end{array}$ & $\begin{array}{l}\text { Site of infarct in the affected } \\
\text { hemisphere }\end{array}$ & $\begin{array}{l}\text { Infarct size } \\
\left(\mathrm{cm}^{2}\right)\end{array}$ & $\begin{array}{l}\text { Vascular pathology of large } \\
\text { arteries in the affected side }\end{array}$ & Main symptom \\
\hline 1 & $55 / \mathrm{M}$ & Large & $\mathrm{L}$ & BG & 1.8 & M1 occlusion & Hemiparesis \\
\hline 2 & $51 / M$ & Large & $\mathrm{L}$ & Putamen & 5.2 & M1 occlusion & Hemiparesis \\
\hline 3 & $75 / \mathrm{F}$ & Large & $\mathrm{L}$ & Frontal $\mathrm{Cx}-\mathrm{SCx}$ & 2.1 & M1 stenosis $(70 \%)$ & Hemiparesis, dysarthria \\
\hline 4 & $57 / \mathrm{M}$ & Large & $\mathrm{R}$ & Frontal SCx & 0.3 & M1 stenosis $(90 \%)$ & Hemiparesis \\
\hline 5 & $52 / \mathrm{M}$ & Large & $\mathrm{L}$ & BG, CR & 1.0 & M1 stenosis $(80 \%)$ & Transient hemiparesis \\
\hline 6 & $69 / \mathrm{M}$ & Large & $\mathrm{R}$ & $\mathrm{SCx}$ & 0.4 & M1 stenosis $(90 \%)$ & Transient hemiparesis \\
\hline 7 & $69 / \mathrm{M}$ & Large & $\mathrm{R}$ & $\mathrm{SCx}$ & 0.4 & M1 stenosis $(80 \%)$ & Transient hemiparesis \\
\hline 8 & $65 / M$ & Large & $\mathrm{R}$ & SCx & 0.3 & ICA occlusion & Asymptomatic \\
\hline 9 & $65 / M$ & Large & $\mathrm{R}$ & BG & 2.2 & ICA stenosis $(>90 \%)$ & Hemiparesis \\
\hline 10 & $68 / M$ & Large & $\mathrm{L}$ & $\mathrm{BG}, \mathrm{SCx}$ & 1.0 & ICA stenosis $(80 \%)$ & Syncope \\
\hline 11 & $71 / \mathrm{M}$ & Large & $\mathrm{L}$ & $\mathrm{BG}, \mathrm{CR}$ & 1.5 & ICA stenosis $(80 \%)$ & Amnesia \\
\hline 12 & $73 / \mathrm{M}$ & Large & $\mathrm{R}$ & Parietal $\mathrm{Cx}-\mathrm{SCx}$ & 6.6 & ICA stenosis $(70 \%)$ & Asymptomatic \\
\hline 13 & $49 / \mathrm{F}$ & Large & $\mathrm{R}$ & Parietal $\mathrm{Cx}-\mathrm{SCx}$ & 5.2 & ICA occlusion & Amaurosis fugax \\
\hline 14 & $35 / \mathrm{M}$ & Large & $\mathrm{R}$ & CR, SCx & 5.9 & ICA stenosis $(90 \%)$ & Hemiparesis \\
\hline 15 & $23 / M$ & Large & $\mathrm{L}$ & $\mathrm{SCx}$ & 0.3 & ICA occlusion & Asymptomatic \\
\hline 16 & $34 / \mathrm{M}$ & Large & $\mathrm{L}$ & Scx, occipital $\mathrm{Cx}-\mathrm{SCx}$ & 12.5 & ICA and PCA occlusion & Hemiplegic migraine \\
\hline 17 & $67 / M$ & Small & $\mathrm{L}$ & $\mathrm{SCx}$ & 0.3 & No significant stenosis & Hemiparesis \\
\hline 18 & $60 / \mathrm{M}$ & Small & $\mathrm{L}$ & SCx & 0.5 & No significant stenosis & Amnesia \\
\hline 19 & $58 / \mathrm{F}$ & Small & $\mathrm{L}$ & $\mathrm{CR}$ & 0.5 & No significant stenosis & Asymptomatic \\
\hline 20 & $53 / \mathrm{F}$ & Small & $\mathrm{L}$ & $\mathrm{SCx}$ & 0.3 & No significant stenosis & Asymptomatic \\
\hline 21 & $52 / \mathrm{F}$ & Small & $\mathrm{L}$ & Thalamus & 0.3 & No significant stenosis & Hemisensory loss, hemiparesis \\
\hline 22 & $58 / M$ & Small & $\mathrm{R}$ & BG & 0.5 & No significant stenosis & Amnesia \\
\hline 23 & $71 / \mathrm{M}$ & Small & $\mathrm{L}$ & $\mathrm{BG}, \mathrm{CR}, \mathrm{SCx}$ & 1.0 & No significant stenosis & Gait disturbance \\
\hline 24 & $57 / \mathrm{M}$ & Small & $\bar{L}$ & Thalamus, BG, CR, SCx & 1.9 & No significant stenosis & Amnesia \\
\hline
\end{tabular}

Large=large vessel disease (atherothrombotic infarction, antiphospholipid syndrome, moyamoya-like vasculopathy); Small=small vessel disease (lacunar infarction, Binswanger's disease); $\mathrm{L}=$ left; $\mathrm{R}=$ right; $\mathrm{BG}=$ basal ganglia; $\mathrm{Cx}=$ cortex; $\mathrm{Scx}=$ subcortex; $\mathrm{CR}=$ corona radiata; $\mathrm{M} 1=$ horizontal trunk of the middle cerebral artery; $\mathrm{ICA}=$ internal carotid artery; $\mathrm{PCA}=$ posterior cerebral artery.

and conventional cerebral angiography were added to provide further information of vascular lesions.

Twelve right handed normal subjects for the MEG study (MEG control group; six men and six women, age range 21 to 57 years) and another 14 age matched normal subjects for the PET study (PET control group; six men and eight women, age range 39 to 73 years) without hearing difficulty and brain disorders also participated. MRI showed no brain lesions in these control subjects. Informed consent was obtained from all patients and control subjects before MEG and PET studies.

MEG STUDY

MEG was performed in all patients and MEG control subjects using a 37 channel neuromagnetometer (Magnes, Biomagnetic Technologies) in a magnetically shielded room. Each subject lay in the lateral position, and the positions of both preauricular points and the nasion as well as the head shape were measured for each subject using a three dimentional digitiser, and a

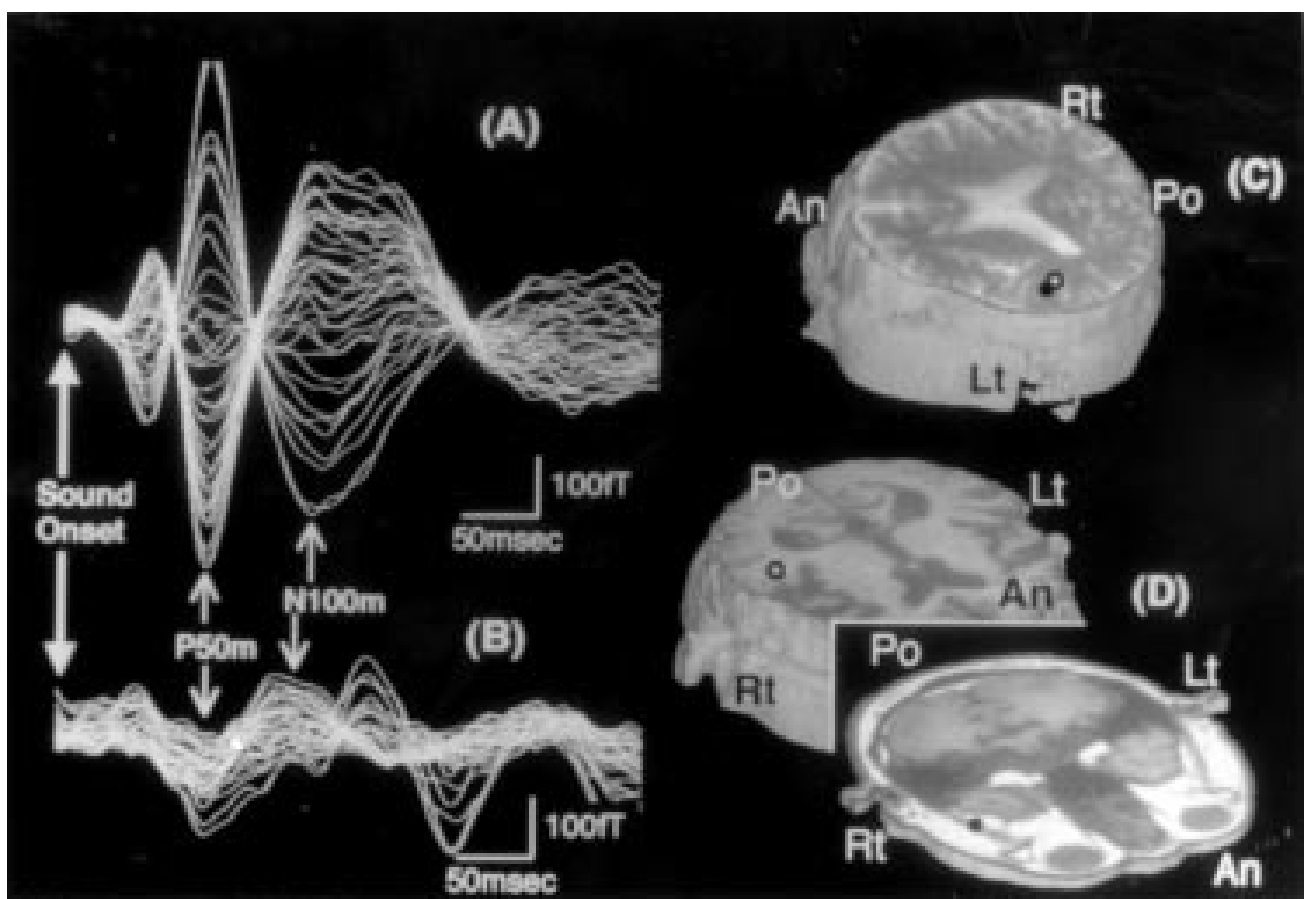

Figure $1 \quad(A, B):$ Auditory evoked magnetic responses over the left hemisphere of a 57 year old woman from the control group $(A)$ and the responses over the right hemisphere of a 57 year old man with a right frontal subcortical infarction (patient 4, B), recorded by 37 channel MEG. $(C, D)$ : Reconstructed three dimensional MRI with magnetic sources for P50m (closed circles) and N100m (open circles) in the 57 year old control subject (C) and Patient 4 (D). An = anterior; Po $=$ posterior; $R t=$ right; $L t=$ left. 

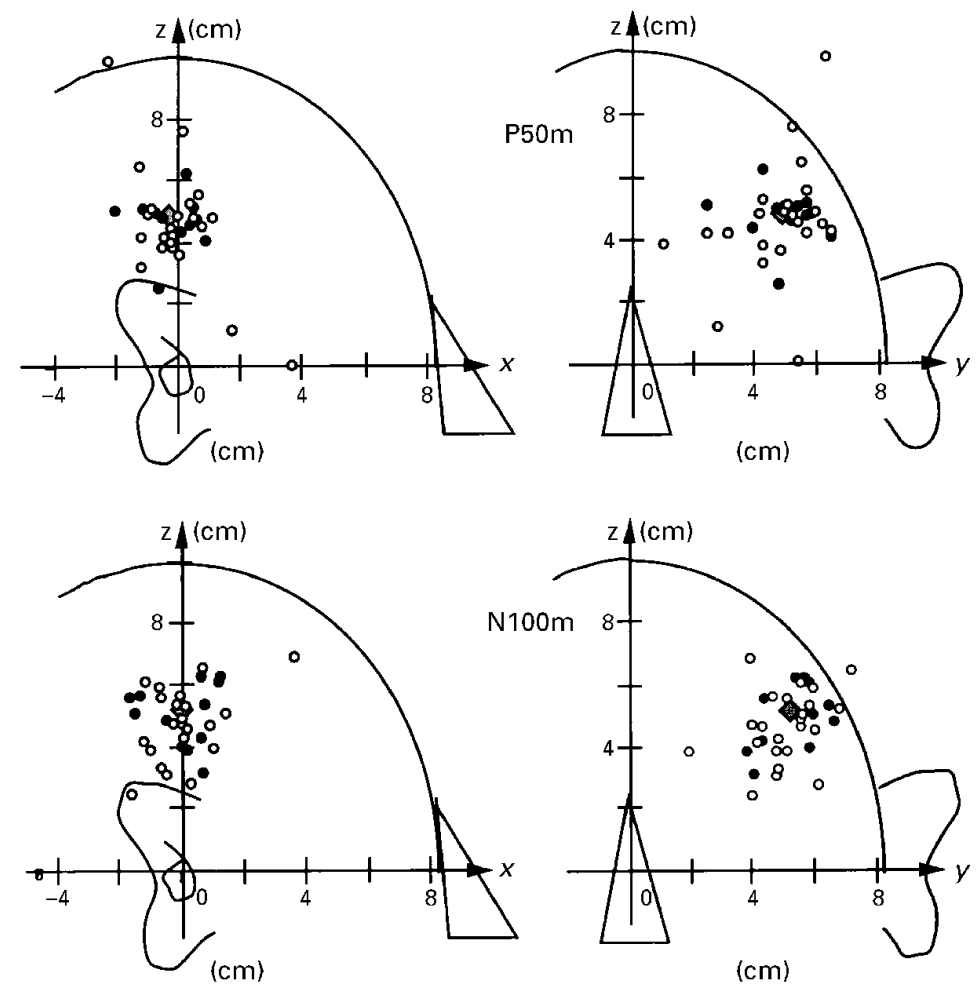

Figure 2 Distribution of the magnetic sources (equivalent current dipoles) of P50m (upper coordinate systems) and N100m (lower coordinate systems) in patients (open circles) and control subjects (closed circles). Rectangles indicate mean source locations for control subjects.

sensor position indicator system. Subjects were instructed to keep their eyes open, to minimise eye movements and eye blinks, and to count silently the number of stimuli. We monitored subjects using a videocamera. Tone bursts of 1 $\mathrm{kHz}$ and $50 \mathrm{~dB}$ sound pressure level at the ear with $400 \mathrm{~ms}$ duration were presented to the patient's ear contralateral to the brain lesion, or the right ear of control subjects, through a $7 \mathrm{~m}$ long plastic tube of $15 \mathrm{~mm}$ inner diameter terminating in an inserted earphone. Interstimulus intervals varied randomly between 1.5 and $2.5 \mathrm{~s}$ around a mean of $2.0 \mathrm{~s}$.

Evoked neuromagnetic fields over the hemisphere contralateral to the stimuli were recorded through a $144 \mathrm{~mm}$ diameter circular Dewer positioned close to the temporal region. The detector array was centred on a point 1.5 $\mathrm{cm}$ superior to the position $\mathrm{T} 3$ of the international 10-20 system, as near as possible to the subject's head. We measured 128 single responses and averaged them with a bandpass of 1 to $55 \mathrm{~Hz}$ and a sampling rate of $520 \mathrm{~Hz}$. The auditory components of $\mathrm{P} 50 \mathrm{~m}$ and $\mathrm{N} 100 \mathrm{~m}$ were identified by polarity reversals in the subsets of the 37 channels. Peaks of P50m and $\mathrm{N} 100 \mathrm{~m}$ were visually identified as the points of maximum amplitude, and within a latency window of $25-60 \mathrm{~ms}$ and $60-220 \mathrm{~ms}$, respectively, after stimulation. The neuronal current sources corresponding to the peak points of these components were modelled by single equivalent current dipoles (ECDs). The location of ECDs was calculated, and ECDs were superimposed on to the MRI using our previously reported technique. ${ }^{14}{ }^{15}$ ECDs with a correlation coefficient $<0.95$ between the measured and theoretical fields were discarded from the analysis.

A three dimensional coordinate system was defined for each subject based on both preauricular points and the nasion. The origin is the midpoint between both preauricular points. The $\mathrm{x}$ axis joins the origin to the nasion, the $\mathrm{y}$ axis passes between the preauricular points, and the $\mathrm{z}$ axis is perpendicular to the $\mathrm{x}-\mathrm{y}$

Table 2 Magnetoencephalographic and positron emission tomographic findings of the patients

\begin{tabular}{|c|c|c|c|c|c|c|c|c|c|c|}
\hline \multirow[b]{2}{*}{ Patient } & \multicolumn{2}{|l|}{ P50m } & \multicolumn{2}{|l|}{ N100m } & \multicolumn{3}{|c|}{ Supratemporal region } & \multicolumn{3}{|c|}{ Entire hemispheric region } \\
\hline & $\begin{array}{l}E C D \\
\text { Distance } \\
(\mathrm{cm})\end{array}$ & $\begin{array}{l}\text { Correlation } \\
\text { coefficient }\end{array}$ & $\begin{array}{l}E C D \\
\text { Distance } \\
(\mathrm{cm})\end{array}$ & $\begin{array}{l}\text { Correlation } \\
\text { coefficient }\end{array}$ & $\begin{array}{l}C B F \\
(\mathrm{ml} / 100 \\
\mathrm{ml} / \mathrm{min})\end{array}$ & $O E F$ & $\begin{array}{l}\mathrm{CMRO}_{2} \\
(\mathrm{ml} / 100 \\
\mathrm{ml} / \mathrm{min})\end{array}$ & $\begin{array}{l}C B F \\
\text { ( } \mathrm{ml} / 100 \\
\mathrm{ml} / \mathrm{min})\end{array}$ & $O E F$ & $\begin{array}{l}\mathrm{CMRO}_{2} \\
\text { ( } \mathrm{ml} / 100 \\
\mathrm{ml} / \mathrm{min})\end{array}$ \\
\hline 1 & Discarded & 0.88 & 3.6 & 0.98 & 27.1 & 0.435 & 1.92 & 22.2 & 0.456 & 1.64 \\
\hline 2 & $\overline{\text { Discarded }}$ & 0.92 & 0.9 & 0.99 & 30.7 & 0.438 & 2.54 & 22.4 & 0.46 & 1.98 \\
\hline 3 & 8.8 & 0.96 & 4.3 & 0.97 & 27.5 & 0.475 & 2.17 & 27.5 & 0.421 & 1.93 \\
\hline 4 & $\overline{6.0}$ & 0.95 & $\overline{0.9}$ & 0.96 & 26.8 & 0.570 & 2.62 & 21.3 & 0.514 & 1.86 \\
\hline 5 & $\overline{2.9}$ & 0.98 & $\underline{2.6}$ & 0.95 & 33.7 & 0.387 & 2.46 & 31.7 & 0.373 & 2.19 \\
\hline 6 & $\frac{1.1}{1.1}$ & 0.96 & 0.8 & 0.99 & 33.5 & 0.540 & 2.54 & 27.7 & 0.496 & 1.94 \\
\hline 7 & 1.6 & 0.99 & 1.3 & 0.99 & 39.7 & 0.441 & 2.56 & 32.5 & 0.441 & 2.09 \\
\hline 8 & 1.1 & 0.99 & 1.5 & 0.99 & 36.0 & 0.573 & 2.37 & 32.5 & 0.499 & 1.85 \\
\hline 9 & 0.8 & 0.99 & 1.5 & 0.99 & 29.4 & 0.508 & 3.27 & 24.4 & 0.485 & 2.58 \\
\hline 10 & 1.1 & 0.99 & 1.6 & 0.99 & 27.4 & 0.394 & 2.01 & 25.5 & 0.397 & 1.83 \\
\hline 11 & 1.3 & 0.99 & 0.5 & 0.99 & 29.3 & 0.444 & 2.12 & 25.3 & 0.424 & 1.73 \\
\hline 12 & 1.3 & 0.99 & 2.4 & 0.98 & 37.4 & 0.384 & 2.40 & 34.0 & 0.353 & 2.00 \\
\hline 13 & 1.6 & 0.99 & $\overline{0.4}$ & 0.99 & 36.4 & 0.433 & 2.15 & 33.3 & 0.430 & 1.90 \\
\hline 14 & 4.6 & 0.95 & Discarded & 0.80 & 25.4 & 0.531 & 1.83 & 25.0 & 0.48 & 1.66 \\
\hline 15 & $\overline{1.4}$ & 0.99 & 3.3 & 0.99 & 38.7 & 0.379 & 3.08 & 34.6 & 0.340 & 2.44 \\
\hline 16 & 1.9 & 0.99 & $\overline{1.9}$ & 0.99 & 34.6 & 0.408 & 2.10 & 27.8 & 0.407 & 1.68 \\
\hline 17 & 1.4 & 0.99 & 1.3 & 0.99 & 23.1 & 0.458 & 1.55 & 24.4 & 0.510 & 1.47 \\
\hline 18 & 2.5 & 0.98 & 2.1 & 0.98 & 35.0 & 0.387 & 1.55 & 31.0 & 0.414 & 1.47 \\
\hline 19 & 0.3 & 0.98 & 1.3 & 0.98 & 53.8 & 0.320 & 2.89 & 47.0 & 0.332 & 2.60 \\
\hline 20 & 1.9 & 0.99 & 1.9 & 0.99 & 45.5 & 0.440 & 3.57 & 31.0 & 0.436 & 2.39 \\
\hline 21 & 2.1 & 0.99 & 1.6 & 0.99 & 43.0 & 0.366 & 2.41 & 35.3 & 0.368 & 1.99 \\
\hline 22 & 0.8 & 0.99 & 0.7 & 0.98 & 41.0 & 0.431 & 3.38 & 34.7 & 0.430 & 2.82 \\
\hline 23 & 4.0 & 0.97 & 1.6 & 0.99 & 21.0 & 0.524 & 1.98 & 16.8 & 0.504 & 1.49 \\
\hline 24 & $\overline{1.1}$ & 0.97 & 0.9 & 0.99 & 21.6 & 0.535 & 2.24 & 19.6 & 0.471 & 1.80 \\
\hline Patients & $2.2(2.0)$ & $0.97(0.03)$ & $1.7(1.0)$ & $0.99(0.01)$ & $33.2(8.0)$ & $0.450(0.069)$ & $2.40(0.53)$ & $28.6(6.5)$ & $0.435(0.055)$ & $1.97(0.37)$ \\
\hline Controls & $1.5(0.7)$ & $0.98(0.01)$ & $1.6(0.3)$ & $0.99(0.004)$ & $41.5(6.9)$ & $0.396(0.047)$ & $2.80(0.38)$ & $34.8(5.7)$ & $0.406(0.039)$ & $2.38(0.20)$ \\
\hline $\mathrm{p}$ Value & NS & NS & NS & NS & 0.0002 & 0.002 & 0.003 & 0.0007 & 0.03 & $<0.0001$ \\
\hline
\end{tabular}

Underlined data on ECD distance indicate abnormal responses. Controls were 12 normal subjects for MEG or 14 normal subjects (28 regions) for PET. Values of patients and controls are means $(\mathrm{SD}) . \mathrm{CBF}=$ cerebral blood flow; $\mathrm{OEF}=$ oxygen extraction fraction; $\mathrm{CMRO}_{2}=$ cerebral metabolic rate of oxygen; $\mathrm{NS}=$ not significant. 


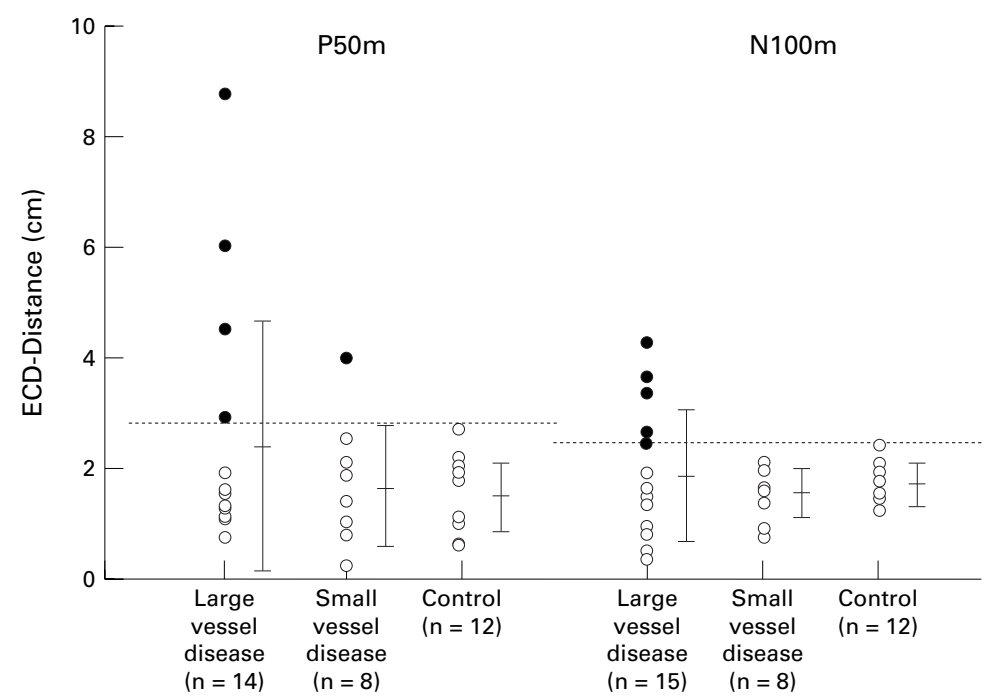

Figure 3 Distances between the equivalent current dipole (ECD) in each patient with large vessel disease, patient with small vessel disease, or control subject and averaged ECD in control subjects (described as ECD-Distance) for P5Om and N100m. Bars indicate SD around the mean. Dotted lines indicate mean $+2 S D$ of control subjects. Closed circles indicate patients with abnormal ECD localisation whose ECD distance exceed mean $+2 S D$ of control subjects.

plane. We regarded the average coordinates of the head size of $12 \mathrm{MEG}$ control subjects as the standard, and corrected the coordinates of ECDs in each patient (or control subject) using the following equation:

$$
\begin{aligned}
& \mathrm{x}=\mathrm{x}_{0} \times \mathrm{x}_{\mathrm{N}} / \mathrm{x}_{\mathrm{n}}, \mathrm{y}=\left(\mathrm{y}_{0} \times \mathrm{y}_{\mathrm{p}} / \mathrm{y}_{\mathrm{p}}\right) \times(-1)^{\star}, \\
& \mathrm{z}=\mathrm{z}_{0} \times\left(\mathrm{xN}^{2}+\mathrm{yP}^{2} / \mathrm{xn}^{2}+\mathrm{yp}^{2}\right)
\end{aligned}
$$

Where $\left(\mathrm{x}_{0}, \mathrm{y}_{0}, \mathrm{z}_{0}\right)=$ coordinates of ECD in each patient before correction; $\mathrm{x}_{\mathrm{n}}=\mathrm{x}$ coordinate of the nasion of each patient; $x_{N}=$ average of $x$ coordinates of the nasion of control subjects; $\mathrm{y}_{\mathrm{p}}=\mathrm{y}$ coordinate of the left preauricular point of each patient; $\mathrm{y}_{\mathrm{P}}=$ average of $\mathrm{y}$ coordinates of the left preauricular point of control subjects; * only for patients with right side lesions.

PET STUDY

PET was performed in all patients and PET control subjects using a HEADTOME-III

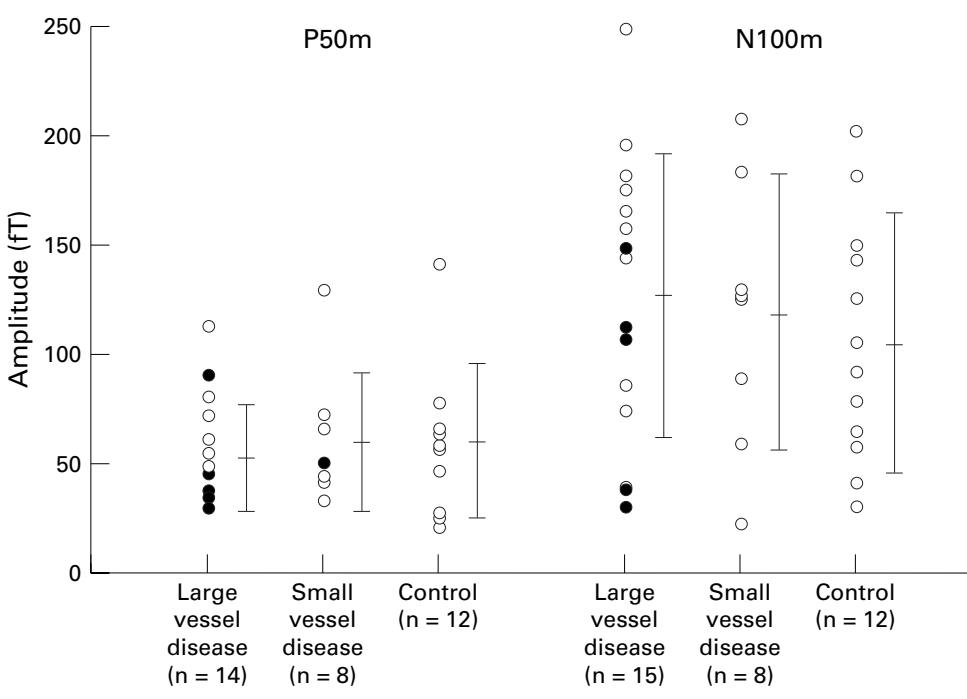

Figure 4 Amplitudes of P5Om and N100m in patients with large vessel disease, patients with small vessel disease, and control subjects. Closed circles indicate patients with abnormal localisation of the equivalent current dipole (ECD) (underlined patients in table 2). Bars indicate means (SD). device (Shimadzu Inc) with a spatial resolution of $8.2 \mathrm{~mm}$. Each subject lay in the supine position with eyes open and without ear plugs in a semidark room. A small cannula was placed in the femoral artery for arterial blood sampling. Patients underwent this study two days before MEG measurements. Regional CBF, oxygen extraction fraction $(\mathrm{OEF})$, and $\mathrm{CMRO}_{2}$ were measured by the ${ }^{15} \mathrm{O}$ steady state technique, and both $\mathrm{OEF}$ and $\mathrm{CMRO}_{2}$ were corrected with cerebral blood volume measured by a single inhalation of $\mathrm{C}^{15} \mathrm{O}$ gas, as previously described. ${ }^{16}{ }^{17}$ An $18 \times 14 \mathrm{~mm}$ rectangular region of interest in the supratemporal cortex ipsilateral to the infarct was identified on an axial slice $50 \mathrm{~mm}$ above the orbitomeatal line by visual inspection based on individual MRI findings. Data for the ipsilateral hemisphere were also estimated from the average of all pixels in the entire hemisphere on the same slice.

\section{STATISTICAL ANALYSIS}

Values are expressed as means (SD). An unpaired $t$ test was used to compare MEG and PET indices. The $\chi^{2}$ test also was used; $\mathrm{p}<0.05$ was accepted as significant.

\section{Results}

CLINICAL AND NEURORADIOLOGICAL PROFILES OF PATIENTS (TABLE 1)

Large vessel disease caused infarcts in 16 of 24 patients; 12 (patients 1-12) had atherosclerotic changes, two (patients 13 and 14) had antiphospholipid syndrome derived arterial lesions, and two (patients 15 and 16) had moyamoya-like vasculopathies. Nine of these 16 patients had internal carotid artery lesions (four occlusions and five stenoses) and seven had middle cerebral artery disease (two occlusions and five stenoses). The remaining eight patients did not have severe stenoses in large arteries and were diagnosed as having small vessel disease; six (patients 17-22) were diagnosed as having lacunar infarction, and two (patients 23 and 24) as having Binswanger's disease.

Infarcts in the affected hemisphere lay mainly in the basal ganglia, corona radiata, and cerebral subcortices. Only four patients (patients 3,12,13, and 16) had cortical infarcts. Infarcts in the contralateral hemisphere were absent or minimal in all patients. The two patients with small vessel disease (patients 23 and 24) had multiple pontine infarcts, including a cerebellopontine angle infarct in patient 23. In the remaining 22 patients, infarcts in the brain stem either were not detected, or were small and limited to the basis pontis.

\section{MEG FINDINGS}

Figure 1 shows typical AEF waveforms from 37 channel MEG recordings of a MEG control subject and one patient (patient 4). Peaks of $\mathrm{P} 50 \mathrm{~m}$ and $\mathrm{N} 100 \mathrm{~m}$ were clearly identified in the $\mathrm{AEF}$ of the control subject, and their ECDs occurred close together in the supratemporal cortex. By contrast, the waveforms of patient 4 did not have clear $\mathrm{P} 50 \mathrm{~m}$ and $\mathrm{N} 100 \mathrm{~m}$ peaks, and the ECD of $\mathrm{P} 50 \mathrm{~m}$ was remote from the supratemporal cortex. We identified ECDs of 


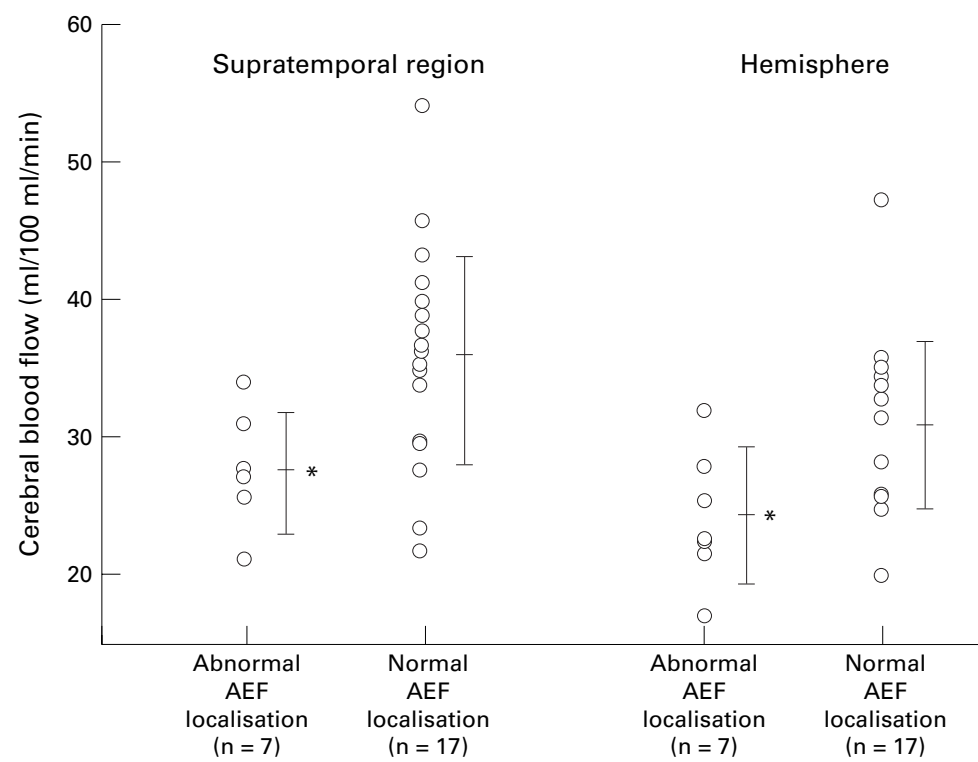

Figure 5 Regional cerebral blood flow in supratemporal and entire hemispheric regions of patients. Patients with abnormal localisation of the equivalent current dipole (ECD) correspond to underlined patients in table 2 . Bars indicate means $(S D) .{ }^{\star} P<0.05 v$ patients with normal ECD localisation. nates of ECDs of P50m $(\mathrm{cm})$ averaged $(0.2$ (1.5), $4.4(1.7)$ and $4.6(2.4)$ in patients and $-0.1(0.9), 5.0(1.1)$ and $4.7(0.9)$ in control subjects. Those of $\mathrm{N} 100 \mathrm{~m}$ averaged 0.1 (1.1), $5.1(1.1)$, and $4.6(1.2)$ in patients and -0.1 (1.0), 5.3 (1.0), and $5.0(1.0)$ in control subjects.

Table 2 and fig 3 show the distances between the ECD of each subject and averaged ECD in control subjects (described as ECD-Distance in the following text, table 2 , and figs 3,6 , and 7). ECD-Distances of P50m exceeded the mean $+2 S D$ of the control subjects $(2.8 \mathrm{~cm})$ in five patients (patients 3, 4, 5, 14, and 23). Four of these five patients had large vessel disease. Correlation coefficients of the P50m ECD in these five patients $(0.96(0.12))$ were much lower than those in the remaining 17 patients (0.99 (0.10), p<0.0001). ECD-Distances of the $\mathrm{N} 100 \mathrm{~m}$ in five patients (patients $1,3,5,12$, and 15) exceeded the mean+2SD of the control subjects $(2.3 \mathrm{~cm})$. All of these patients had large vessel disease. Correlation coefficients of the ECD in these five patients $(0.97$ (0.17)) were much lower than those in the remaining 18 patients $(0.99(0.10, \mathrm{p}<0.01))$. We defined patients with an ECD-Distance over the mean $+2 \mathrm{SD}$ of the control subjects or those whose ECD was discarded as the abnormal AEF group in the following analyses. Four patients (patients 1,3,5, and 14) had abnormal AEF responses for both $\mathrm{P} 50 \mathrm{~m}$ and $\mathrm{N} 100 \mathrm{~m}$, three (patients 2, 4, and 23) had abnormal AEF responses only for $\mathrm{P} 50 \mathrm{~m}$, and two (patients 12, 15) for only N100m (table 2).

Amplitudes of $\mathrm{P} 50 \mathrm{~m}$ as well as $\mathrm{N} 100 \mathrm{~m}$ varied widely in both patients and control subjects, and there were no significant differences in these amplitudes between patients (57 subjects were distributed. $\mathrm{x}, \mathrm{y}$, and $\mathrm{z}$ Coordi-



Supratemporal CBF
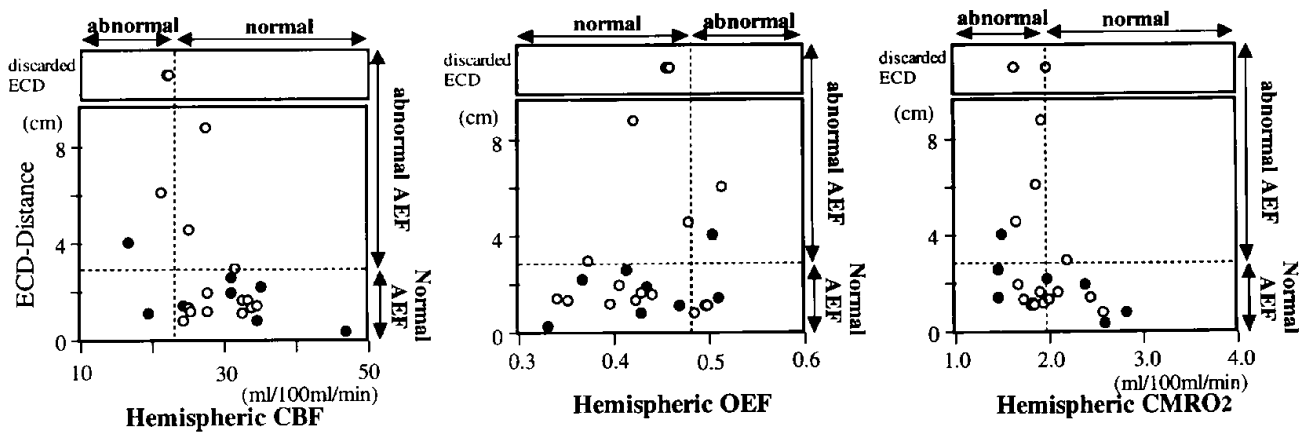

Figure 6 Scattergrams between PET indices in the supratemporal or entire hemispheric regions and the ECD-Distance of P50m in patients with large vessel disease (open circles) and with small vessel disease (closed circles). Equivalent current dipoles (ECDs) with a correlation coefficient of $<0.95$ between the measured and theoretical fields were discarded. 

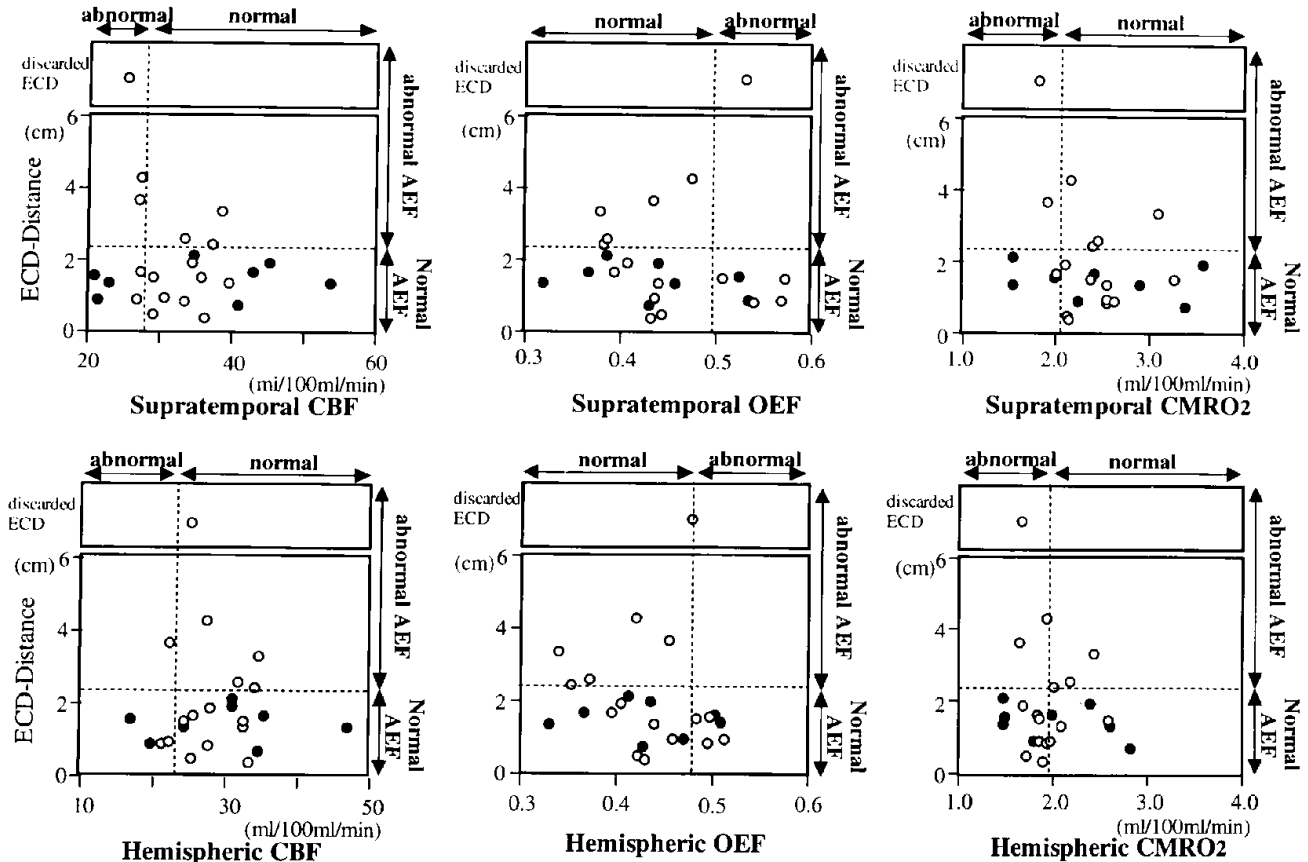

Figure 7 Scattergrams between PET indices in the supratemporal or entire hemispheric regions and the ECD-Distance of N100m in patients with large vessel disease (open circles) and with small vessel disease (closed circles). An equivalent current dipole (ECD) with a correlation coefficient of $<0.95$ between the measured and theoretical fields was discarded.

(27) fT for P50m and 123 (62) fT for N100m) and control subjects (60 (35) fT for P50m and 105 (58) fT for N100m, fig 4). The above defined abnormal AEF patients had smaller amplitudes of $\mathrm{P} 50 \mathrm{~m}$ and $\mathrm{N} 100 \mathrm{~m}$ than patients with normal AEF localisation $(0.05<\mathrm{p}<0.1)$. There were also no significant differences in latency of $\mathrm{P} 50 \mathrm{~m}$ and $\mathrm{N} 100 \mathrm{~m}$ between patients (43 (10) $\mathrm{ms}$ for $\mathrm{P} 50 \mathrm{~m}$ and 94 (15) $\mathrm{ms}$ for $\mathrm{N} 100 \mathrm{~m})$ and control subjects $(43(10) \mathrm{ms}$ for P50m and 90 (13) $\mathrm{ms}$ for $\mathrm{N} 100 \mathrm{~m}$ ).

PET FINDINGS

Regional $\mathrm{CBF}$ and $\mathrm{CMRO}_{2}$ were significantly lower, and regional $\mathrm{OEF}$ was significantly higher both in the supratemporal and entire hemispheric regions in stroke patients compared with the 14 PET control subjects (table 2). We defined regional $\mathrm{CBF}$ and $\mathrm{CMRO}_{2}$ below "mean-2SD" of the control group and regional OEF over mean+2SD of the control group as abnormal data in the following analyses.

Patients with abnormal P50m AEF responses $(n=7)$ had much lower regional $\mathrm{CBF}$ (27.5 (4.0) $\mathrm{ml} / 100 \mathrm{ml} / \mathrm{min}$ in the supratempo$\mathrm{ral}$ region and $23.8(4.8) \mathrm{ml} / 100 \mathrm{ml} / \mathrm{min}$ in the entire hemispheric region) than those with normal AEF responses $(n=17,35.6(8.1)$ $\mathrm{mll} / 100 \mathrm{ml} / \mathrm{min}$, and $30.6(6.2) \mathrm{ml} / 100 \mathrm{ml} / \mathrm{min}$ respectively; $\mathrm{p}<0.02$ in both regions, fig 5). Alternatively, there was a significant relation between an abnormal P50m AEF and abnormal regional $\mathrm{CBF}$ in the supratemporal region $(\mathrm{p}<0.01)$ and in the entire hemispheric region $(\mathrm{p}<0.005)$ by $\chi^{2}$ test (fig 6). When the same analysis was made using 16 patients with large vessel disease, patients with abnormal P50m $\mathrm{AEF}$ responses also had significantly lower regional $\mathrm{CBF}$ than those with normal re- sponses $(p<0.01$ in the supratemporal region and $\mathrm{p}<0.05$ in the entire hemispheric region). Patients with abnormal responses also had higher regional OEF $(0.480(0.065)$ in the supratemporal region and $0.458(0.049)$ in the entire hemispheric region) and lower regional $\mathrm{CMRO}_{2}(2.22(0.32) \mathrm{ml} / 100 \mathrm{ml} / \mathrm{min}$ in the supratemporal region and $1.82(0.24) \mathrm{ml} / 100$ $\mathrm{ml} / \mathrm{min}$ in the entire hemispheric region) compared with those with normal responses (supratemporal OEF, 0.438 (0.068); hemispheric OEF, 0.426 (0.056); supratemporal $\mathrm{CMRO}_{2}, 2.47(0.62) \mathrm{ml} / 100 \mathrm{ml} / \mathrm{min}$; hemispheric $\mathrm{CMRO}_{2}, 2.04(0.40) \mathrm{ml} / 100 \mathrm{ml} / \mathrm{min}$ ), but this difference was not significant.

Patients with abnormal N100m AEF responses had insignificantly lower regional $\mathrm{CBF}$, OEF, and $\mathrm{CMRO}_{2}$ compared with patients with normal responses (fig 7).

\section{Discussion}

There are two major new findings in our study. Firstly, in some patients with large vessel cerebrovascular disease and a small infarct but without any auditory cortical infarcts, the magnetic sources of $\mathrm{P} 50 \mathrm{~m}$ and $\mathrm{N} 100 \mathrm{~m}$ were not accurately identified. Distribution of $\mathrm{P} 50 \mathrm{~m}$ sources varied more widely than those of N100m. Secondly, decreased cerebral perfusion in the auditory cortex and neighbouring territories, as evaluated by PET, correlated with abnormal source localisation of $\mathrm{P} 50 \mathrm{~m}$, but not with that of $\mathrm{N} 100 \mathrm{~m}$. Thus cerebral perfusion disorders due to large vessel disease tend to affect AEFs, especially the middle latency components.

AUDITORY RESPONSES IN STROKE

Auditory fibres enter the brain stem at the level of the inferior cerebellar peduncle, ascending 
through the cochlear nuclei, lateral lemniscus, inferior colliculus, and medial geniculate body, and finally reach the transverse gyri (Heschl) in the supratemporal cortex, the primary auditory area, via the auditory radiations. Any lesions in the pathway may cause auditory dysfunctionfor example, supratemporal infarcts affect both magnetic AEF and electric AEP. ${ }^{1011} 1819$ Lesions of the distal auditory radiations also have been reported to affect AEP. ${ }^{19}$

Our results are unique in that cerebral haemodynamic disorders in and around the supratemporal cortex also cause abnormal AEF responses. The abnormal responses in our patients did not result from heterogeneity of head conductivity or interference of skin potentials, which affect electric evoked potentials but not magnetic fields. Some reports have suggested the possibility of compensatory reorganisation of sensory maps in the human cortex in response to brain injury and infarct. $^{2021}$ However, most of the present abnormal ECDs that were remote from the auditory cortex did not lie in the cerebral cortex, and therefore, cortical reorganisation is not a reasonable explanation for the abnormal localisation of ECDs. In this study, patients with abnormal AEF responses had much lower ECD correlation coefficients and their waveforms did not show symmetric reversals of polarity at the peaks (fig 1 ). These abnormalities probably caused the abnormal source localisation.

Large vessel disease was a common characteristic of most of the patients with abnormal AEF responses. Localisation of their infarcts varied widely, and all of them were remote from the auditory cortex. Small infarcts in the basal ganglia did not seem to involve the auditory radiations. However, PET detectable territories of decreased perfusion covered both the auditory cortex and auditory radiations in each patient; therefore these flow deficits were thought to be responsible for the abnormal AEF responses.

One patient with an abnormal AEF (patient 23) did not have large vessel disease but a cerebellopontine angle infarct. Disturbance of $\mathrm{AEF}$ in this patient may have resulted from direct damage of the primary auditory neurons.

AEF RESPONSES AND CEREBRAL HAEMODYNAMICS PET permits quantitative evaluation of cerebral circulation and metabolism, and has been widely used as a tool for three dimensional brain functional imaging. Rhythmical electric activities of quantitative EEG seem to correlate well with PET indices. ${ }^{13}$ Visual evoked potentials also correlate with regional $\mathrm{CBF}$ or local cerebral glucose metabolism in hemianopsic patients. ${ }^{12}$ In this study, we expected a similar relation between AEF and PET indices-for example, the presence of a threshold value of regional $\mathrm{CBF}$ or $\mathrm{CMRO}_{2}$ below which an abnormal AEF appears.

An abnormal P50m AEF often appeared in patients with a regional $\mathrm{CBF}$ below the mean-2SD of CBF in control subjects: 27.7 $\mathrm{ml} / 100 \mathrm{ml} / \mathrm{min}$ for supratemporal $\mathrm{CBF}$ and
$23.4 \mathrm{ml} / 100 \mathrm{ml} / \mathrm{min}$ for the entire hemispheric CBF. These values are equivalent to the ischaemic threshold for reversible neurological deficits in experimental animals. ${ }^{22}$ Alternatively, AEF responses were generally normal in patients with supratemporal or entire hemispheric CBF over $30 \mathrm{ml} / 100 \mathrm{ml} / \mathrm{min}$ (fig 4). Significant correlations between $\mathrm{AEF}$ and hemispheric $\mathrm{CBF}$ suggest that haemodynamic disorders in the territories surrounding the auditory cortex including the medial geniculate body and auditory radiations also affect AEF.

However, $\mathrm{CMRO}_{2}$, another PET index reflecting brain function, did not have a clear correlation with AEF in this study. Some patients with low regional $\mathrm{CBF}$ had extremely high OEF for maintenance of normal $\mathrm{CMRO}_{2}$ but still had abnormal AEF responses. The reasons for this phenomenon remain unclear.

Although most of the present patients had small infarcts without obvious brain atrophy, large vessel diseases can cause decreases in brain volume in the affected hemisphere. Thus we cannot exclude the possibility that, besides haemodynamic disorder, changes in brain volume contribute to the difficulties in identifying magnetic sources of P50m or N100m to some extent.

\section{DIFFERENCES IN RESPONSES BETWEEN P50M AND} $\mathrm{N} 100 \mathrm{M}$

The previous AEF studies from normal human volunteers usually focused on $\mathrm{N100m}$, which was the largest and most often observed peak in the waveforms. ${ }^{3-68}{ }^{9}$ P50m usually has a smaller amplitude as was shown in this study, and accordingly seems to be easily affected by mild brain damage. Thus P50m may be a more sensitive indicator of mild ischaemia in the auditory cortex. This hypothesis is consistent with the present results that abnormal source mapping is more prominent in $\mathrm{P} 50 \mathrm{~m}$ than in $\mathrm{N} 100 \mathrm{~m}$. A greater decrease in regional CBF may be needed to find abnormal source mapping of $\mathrm{N} 100 \mathrm{~m}$.

Although the origins of $\mathrm{P} 50 \mathrm{~m}$ and $\mathrm{N} 100 \mathrm{~m}$ remain controversial, some reports suggest the possibility of separate origin for these two components. ${ }^{23}$ Five patients (patients 2, 4, 12, 15,23 ) showed an abnormal AEF response for only one of these two components in the present study, also suggesting the separate generator sources of $\mathrm{P} 50 \mathrm{~m}$ and $\mathrm{N100m}$. Some reports indicate that abnormalities in middle latency responses are associated with subcortical lesions, or cortical lesions extensive enough to denervate thalamic projection nuclei. ${ }^{24}$ In the present study, territories of decreased perfusion detectable by PET in patients with large vessel disease often covered the subcortex surrounding the auditory cortex. Thus subcortical damage may contribute to more severe change of P50m than $\mathrm{N} 100 \mathrm{~m}$ to some extent.

LIMITATIONS IN THE PRESENT STUDY

We did not routinely measure the AEF in the unaffected hemisphere of stroke patients to shorten time for MEG measurement and lighten the physical burden of patients. One patient with abnormal ECD localisation in his 
affected hemisphere had normal ECD localisation in the unaffected hemisphere, and AEF in the unaffected hemisphere was not measured in the remaining eight patients with abnormal AEF response. More precise data of the ECD localisation in the unaffected hemisphere would have brought greater information on the relation between AEF and stroke features.

Stroke patients generally have some disadvantages for MEG measurement, such as alterations in spontaneous cortical activity, decreased cooperation, and motor restlessness during measurement. Although we excluded patients without sufficient intellect or endurance for the present study and all the patients were cooperative, the above disadvantages, especially motor restlessness, might influence the ECD correlation coefficients and identification of $\mathrm{P} 50 \mathrm{~m}$ and $\mathrm{N} 100 \mathrm{~m}$ from waveforms to some extent. Aging is another factor which can affect MEG findings. Six of nine patients with abnormal AEF response were under 60 years old, and thus aging does not seem to be a major cause of abnormal localisation of ECD in the present study.

There are some limitations of the control subjects-namely, the fewer subjects and younger age structure than patients. A larger number of controls might represent the healthy population more accurately, and increase the significance of statistical analyses. Although several limitations seem to make our results complicated, we think that the present study can pave the way for further studies on MEG and stroke patients, which have been scarcely reported until now. In a future study, we will involve better age and sex matching of patients and controls.

In conclusion, this is the first combined study of MEG and PET to show a significant correlation between AEF responses in stroke patients and their PET indices. During the era of electric AEPs, neurologists often examined the early components for a topographic diagnosis of brain stem ischaemia or haemorrhage. By contrast, they paid little attention to the middle and long latency components for evaluation of stroke, partly because of technical difficulties in the recording of these components. MEG permits the detection of exact generator areas of these components without major technical problems. This improvement will help clarify the effect of the topography of infarcts or cerebral haemodynamic changes on sensory maps in the human brain.

This work was supported in part by a Research Grant for Cardiovascular Diseases (8A-1, to S I) from the Ministry of Health and Welfare, Japan. We thank Dr Hiroshi Shigeto, Department of Neurology, Kyushu University and Ms Yuko Somehara, Biomedical Division, Sumitomo Metal Ind, Ltd, for their technical assistance with MEG, Dr Masayuki Sasaki, Department of Radiology, Kyushu University, for his technical assistance with PET, and Dr Michael Carrithers for editing the English.

1 Reite M, Edrich J, Zimmerman JT, et al. Human magnetic auditory evoked fields. Electroencephalogr Clin Neurophysiol 1978;45:114-7

2 Picton TW, Hillyard SA, Krausz HI, Galambos R. Human auditory evoked potentials. I: Evaluation of components. Electroencephalogr Clin Neurophysiol 1974;36:179-190.

3 Hari R, Aittoniemi K, Järvinen ML, et al. Auditory evoked transient and sustained magnetic fields of the human brain. Localization of neural generators. Exp Brain Res 1980;40: 237-40.

4 Farrel DE, Tripp JH, Norgren R, et al. A study of the auditory evoked magnetic field of the human brain. Electroencephalogr Clin Neurophysiol 1980;49:31-7.

5 Romani GL, Williamson SJ, Kaufman L, et al. Characterization of the human auditory cortex by the neuromagnetic tion of the human auditory cortex by the
method. Exp Brain Res 1982;47:381-93.

6 Yamamoto T, Williamson SJ, Kaufman L, et al. Magnetic localization of neuronal activity in the human brain. Proc localization of neuronal activity in the
Natl Acad Sci USA 1988;85:8732-6.

7 Reite M, Teale P, Zimmerman J, et al. Source location of a $50 \mathrm{msec}$ latency auditory evoked field component. Electroencephalogr Clin Neurophysiol 1988;70:490-8.

8 Pantev C, Hoke M, Lehnertz K, et al. Identification of sources of brain neuronal activity with high spatiotemporal resolution through combination of neuromagnetic source ocalization (NMSL) and magnetic resonance imaging (MRI). Electroencephalogr Clin Neurophysiol 1990;75:17384.

9 Papanicolaou AC, Baumann S, Rogers RL, et al. Localization of auditory response sources using magnetoencephalography and magnetic resonance imaging. Arch Neurol 1990;47:33-7.

10 Leinonen L, Joutsiniemi SL. Auditory evoked potentials and magnetic fields in patients with lesions of the auditory cortex. Acta Neurol Scand 1989;79:316-25.

11 Mäkelä JP, Hari R, Valanne L, et al. Auditory evoked magnetic fields after ischemic brain lesions. Ann Neurol 1991;30:76-82

12 Celesia GG, Polcyn RD, Holden JE, et al. Visual evoked potentials and positron emission tomographic mapping of regional cerebral blood flow and cerebral metabolism: can the neuronal potential generators be visualized? Electroencephalogr Clin Neurophysiol 1982;54:243-56.

13 Nagata K, Tagawa K, Hiroi S, et al. Electroencephalographic correlates of blood flow and oxygen metabolism provided by positron emission tomography in patients with cerebral infarction. Electroencephalogr Clin Neurophysiol 1989;72:16-30.

14 Morioka T, Yamamoto T, Katsuta T, et al. Presurgical threedimensional magnetic source imaging of the somatosensory cortex in a patient with a peri-Rolandic lesion: technisory cortex in a patient with a peri-Rol
cal note. Neurosurgery 1994;34:930-4.

15 Minami T, Gondo K, Yamamoto T, et al. Magnetoencephaographic analysis of rolandic discharges in benign childhood epilepsy. Ann Neurol 1996:39;326-34.

16 Fujii K, Sadoshima S, Okada Y, et al. Cerebral blood flow and metabolism in normotensive and hypertensive patients with transient neurologic deficits. Stroke 1990;21:283-90.

17 Yao H, Sadoshima S, Ibayashi S, et al. Leukoaraiosis and dementia in hypertensive patients. Stroke. 1992;23:1673-7.

18 Knight RT, Hillyard SA, Woods DL, et al. The effects of frontal and temporal-parietal lesions on the auditory evoked potential in man. Electroencephalogr Clin Neurophysiol 1980;50:112-24.

19 Scherg M, Von Cramon D. Evoked dipole source potentials of the human auditory cortex. Electroencephalogr Clin Neurophysiol 1986;65:344-60.

20 Yang TT, Gallen C, Schwartz B, et al. Sensory maps in the human brain. Nature 1994;368:592-3.

21 Lewine JD, Astur RS, Davis LE, et al. Cortical organization in adulthood is modified by neonatal infarct: a case study. in adulthood is modified by

22 Jones TH, Morawetz RB, Crowell RM, et al. Thresholds of focal cerebral ischemia in awake monkeys. $\mathcal{F}$ Neurosurg 1982;54:773-82.

23 Pelizzone M, Hari R, Mäkelä JP, et al. Cortical origin of middle-latency auditory evoked responses in man. Neurosci Lett 1987;82:303-7.

24 Woods DL, Clayworth CC, Knight RT, et al. Generators of middle- and long-latency auditory evoked potentials: implications from studies of patients with bitemporal lesions. Electroencephalogr Clin Neurophysiol. 1987;68:13248 . 